\title{
A TELEVISÃO E A LUDICIDADE: UMA MEDIAÇÃO NECESSÁRIA NA EDUCAÇÃO INFANTIL
}

Susana Angelin Furlan ${ }^{1}$, José Milton de Lima ${ }^{2}$, Jéssika Naiara da Silva ${ }^{3}$, Márcia Regina Canhoto de $\operatorname{Lima}^{(4)}$.

${ }^{1}$ Discente em Educação Física pela FCT/UNESP. ${ }^{2}$ Docente na FCT/UNESP, departamento de Educação. ${ }^{3}$ Mestranda em Educação pela FCT/UNESP. ${ }^{4}$ Docente na FCT/UNESP, departamento de Educação Física. E-mail: susana dp@hotmail.com. Conselho Nacional de Desenvolvimento Científico e Tecnológico - CNPq.

\section{RESUMO}

A pesquisa investigou as concepções das educadoras sobre culturas lúdicas e as manifestações televisivas que as crianças apresentam, visando uma mediação na Educação Infantil que valorize a criança como sujeito social, produtora de cultura. Partimos do pressuposto que a brincadeira é atividade essencial para o desenvolvimento das crianças e importante forma de expressão de sua cultura. Outro pressuposto é que a televisão está inserida no cotidiano, modificando o repertório lúdico infantil. Adotou-se como metodologia, a pesquisa qualitativa do tipo etnográfica, fundamentando-se na Sociologia da infância. Verificou-se uma apreensão das educadoras em mediar os conteúdos televisivos considerando-os em seus aspectos negativos, verbalizaram que a ludicidade é importante, mas não tomaram como indispensável na prática educativa, no máximo desvirtuam, empregando-a como meio para aprendizagem em outras áreas. Este encaminhamento não satisfez as crianças que não se sentiram contempladas em suas especificidades, buscando espaços clandestinos para vivências da ludicidade e dos conteúdos midiáticos.

Palavras-chave: Ludicidade, Infância, Televisão, Educação infantil, Sociologia da Infância.

\section{INTRODUÇÃO E OBJETIVOS}

O artigo intitulado "A televisão e a Ludicidade: uma mediação necessária na Educação Infantil" mostra os resultados alcançados com a pesquisa "Cultura lúdica e mediações no contexto escolar", realizada com aproximadamente 180 alunos, de 3 a 5 anos pertencentes as turmas do Infantil I e II, de oito educadoras, em uma instituição de Educação Infantil no município de Álvares Machado - SP.

Essa pesquisa teve como objetivos principais compreender a concepção que as educadoras têm sobre as atividades lúdicas e a mediação que pode ser feita a partir do conhecimento das manifestações televisivas apresentadas pelos seus alunos.

Entendemos que o processo de educação não acontece unicamente dentro das instituições de ensino, visto que a família, os colegas, o contexto social e cultural em que a pessoa está inserida são também responsáveis pela socialização e formação da pessoa. É no ambiente de relações entre pessoas, objetos, costumes e hábitos que nos formamos como seres humanos, 
construímos e identificamos nossas próprias vontades e gostos diante de toda a realidade apresentada.

Desta maneira, a Educação Infantil, é um lugar especial, pois é onde a criança se insere, de maneira mais ampla com hábitos, crenças, valores, etnia, e outros aspectos diferentes dos seus, tornando-se assim um lugar privilegiado para a socialização e apropriação da cultura. É nesse contexto específico e de grande relevância social que desenvolvemos a pesquisa, visto que é inegável o contato das crianças e as suas manifestações a partir dos meios de comunicação de massa, especialmente a televisão, neste ambiente das primeiras relações sociais.

A televisão é a forma de entretenimento presente na maioria das casas, fato constatado por meio das mudanças econômicas, sociais, culturais que provocaram profundas transformações nos espaços sociais e na vida das crianças. Desse modo, a nova companhia da maioria das crianças passou a ser a televisão - meio de informação, entretenimento, desenvolvimento de hábitos e fomentadora das culturas da infância.

Assim para alcançar os objetivos desta pesquisa foi necessário conhecer e considerar a realidade em que as crianças estão inseridas, pois as culturas lúdicas estão diretamente ligadas às experiências e vivências, ou seja, são representações do seu meio sócio-cultural. As crianças não nascem sabendo brincar, elas vão aprendendo com pais, os irmãos mais velhos, vizinhos, professores e pares, entre outros.

Dessa forma, é preciso reconhecer as diferenças e aproveitar o espaço privilegiado e humanizador da Educação Infantil. Faz-se necessário aos educadores identificar as ações da mídia e problematizar para que o desenvolvimento das crianças aconteça gradualmente e com qualidade. Assim, é preciso acreditar que cada educador tem o papel de mediar às relações das crianças com suas respectivas interpretações das influências midiáticas.

\section{METODOLOGIA}

Para alcançar os objetivos propostos pela pesquisa, adotou-se a metodologia qualitativa, pois não tinha como objetivo enumerar e/ou medir dados coletados. Em relação aos estudos que empregam uma metodologia qualitativa, Richardson $(1989$, p. 6) destaca que

[...] podem descrever a complexidade de determinado problema, analisar a interação de certas variáveis, compreender e classificar processos dinâmicos vividos por grupos sociais, contribuir no processo de mudança de determinado grupo e possibilitar, em maior nível de profundidade, o entendimento das particularidades do comportamento dos indivíduos. 
Sendo assim, apoiou-se na etnografia como metodologia orientadora. Para Lüdke e André (1986, p. 6), esse percurso "tem um sentido muito próprio: é a descrição de um sistema de significados culturais de um determinado grupo", a partir do qual o ensino deve ser pensado dentro de um contexto cultural amplo. Desse modo, a etnografia implicou em: estar no local, participar, observar, conversar e registrar as experiências por escrito. Viégas (2007, p.104) destaca que a

etnografia é um método de pesquisa oriundo da antropologia social, cujo significado etimológico pode ser "descrição cultural". Assim, ela representa a tentativa de estudar a sociedade e a cultura, seus valores e práticas, a partir de sua "descrição densa", entendida como mais do que a mera compilação de fatos externos ao pesquisador.

Em relação aos procedimentos metodológicos, a pesquisa utilizou técnicas de observação, entrevistas, questionários, levantamento bibliográfico e diário de campo.

No tocante, a observação também foi um importante componente de compreensão da realidade e de suas estruturas organizacionais. Para Richardson (1989, p. 41), “a observação, quando adequadamente conduzida, pode revelar inesperados e surpreendentes resultados que, possivelmente, não seriam examinados em estudos que utilizassem técnicas diretivas".

Desse modo, a metodologia e os procedimentos adotados foram utilizados e aplicados no trabalho de campo realizado. Tal processo contemplou oito turmas de Educação Infantil, entre elas crianças de três a cinco anos de idade, pertencentes ao Infantil I e Infantil II, totalizando aproximadamente 180 crianças e oito educadoras.

As observações aconteceram uma vez por semana, durante todo o período letivo. A pesquisadora acompanhou, em média de cinquenta minutos, as atividades lúdicas das turmas e anotava em diário de campo as relações entre crianças e adultos, e crianças e crianças, observando e registrando atitudes, diálogos e expressões. Uma parte do arcabouço teórico foi desenvolvido em conjunto com os componentes do Grupo de pesquisa "Cultura Corporal: Saberes e Fazeres", com encontros realizados quinzenalmente no CEPELIJ (Centro de Estudo e Pesquisa em Educação, Ludicidade, Infância e Juventude).

A pesquisa por ser feita com crianças e educadoras está apoiada no Protocolo do Comitê de Ética em Pesquisa (CEP): Processo no 71/2009. 


\section{RESULTADOS}

Durante as observações, as crianças apresentaram manifestações televisivas em suas culturas lúdicas, sejam através dos brinquedos que traziam para a escola, ou mesmo em artefatos culturais que eram estampados com os desenhos animados, como: camisetas, boné, e mochilas.

As brincadeiras das crianças são repletas de elementos oriundos da mídia televisiva. Conforme o relato de um menino que pegando uma máscara do Batman, propôs para os colegas, brincar de esconde-esconde do personagem, essa brincadeira teve as mesmas regras da brincadeira tradicionalmente conhecida, porém percebeu-se que as crianças ressignificaram a brincadeira com aquela representação do desenho animado. Quem escondia estava se escondendo do Batman e aquela criança que procurava estava procurando, não só os seus colegas, mas sim o Coringa, e outros malfeitores do desenho animado.

Através desse relato notou-se como uma brincadeira tradicional no repertório lúdico daquelas crianças, pode se tornar mais divertida e interessante, quando ressignificada usando o conteúdo da televisão como matéria-prima de sua imaginação.

As educadoras através de uma entrevista, quando perguntadas qual era a sua concepção sobre a presença da televisão nas culturas lúdicas das crianças, responderam que essa relação era prejudicial, pois os conteúdos eram na sua maioria violentos e impróprios para a idade das mesmas.

Podemos associar tal posicionamento das professoras ao que Buckingham (2007) apresenta em seu livro "Crescer na era das mídias eletrônicas" como tese da "morte da infância" que se manifesta em uma típica oposição a imprensa e os meios eletrônicos, mais especificamente a televisão. Nesta visão, este meio de comunicação é considerado prejudicial, pois segundo os autores deste discurso, há a "quebra das barreiras" entre os meios adulto e infantil, a criança tem acesso ao mundo adulto precocemente, perdendo sua infância. Buckingham (2007) analisa as descrições de Steinberg \& Kincheloe (1997) e destaca que elas se alinham a noção mais tradicional de efeito da mídia, a relação de influência da violência nas telas.

Porém, quando as educadoras dizem que os conteúdos que as crianças manifestam são violentos e impróprios para a idade delas, sugerem que a mediação em casa, dos pais ou responsáveis não está sendo realizada, colocando a culpa pela falta de conversa, discussão, conscientização somente nos pais, ou responsáveis.

Também foram aplicadas entrevistas abertas e ilustrações, para que as crianças pudessem desenhar quais eram as suas preferências televisivas. Os conteúdos preferidos mais citados foram 
Super-carros, Dora aventureira e Pica-pau. Demonstrando que as preferências estão em conteúdos tidos como próprios para a idade, desenhos animados, que podem alimentar a sua imaginação com as histórias que apresentam.

Além disso, a investigação revelou que as crianças fantasiam com os personagens da televisão, como exemplo, destacamos um fato ocorrido num dia de observação em que uma das crianças pediu para ser chamado de Ben10, ao invés de seu nome, numa brincadeira com a pesquisadora.

\section{DISCUSSÕES}

A Sociologia da Infância considera a criança como um sujeito social com características próprias, que percebe o mundo de maneira distinta do adulto e que, além disso, tem diferentes formas de comunicação e interação com as pessoas e objetos, expressos através do brincar. Redin (2009, p. 123) explica que por meio da "[...] brincadeira a criança mergulha na vida, criando um espaço que expressa, que atribui sentido e significado aos acontecimentos". Sarmento (2003, p.15) acrescenta que diferentemente aos adultos “[...] entre brincar e fazer coisas sérias não há distinção, sendo o brincar muito do que as crianças fazem de mais sério".

A criança, no entanto, não nasce sabendo brincar, esse tipo de atividade não é algo inerente ao ser humano, mas uma atividade repleta de significação social que necessita ser aprendida assim como tantas outras (BROUGÈRE, 1998). Nesta perspectiva, os conteúdos televisivos que precisam ser mediados também pode ser apreendidos, valorizando desta maneira o que a criança traz para dentro da sala de aula.

É fato que a partir do momento em que a televisão ganhou espaço no cotidiano das famílias, surgiram questionamentos sobre os seus malefícios e os seus benefícios na vida das crianças. Muito se comentou, como aponta Girardello (1999), sobre a relação com a imaginação das crianças, ser ou não "danificada" pela televisão. Como se a TV "anestesiasse" a imaginação, limitando-a quanto à criação de imagens já que estas vêm prontas. Para a autora a televisão alimenta a imaginação das crianças, os enredos tornam-se pré-roteiros para a imaginação, ou seja, imaginar a partir das histórias, criando novas formas de brincar.

Portanto, se a brincadeira é uma atividade social, a escola enquanto importante espaço para socialização torna-se imprescindível para o desenvolvimento de relações, trocas de experiências e formação de valores e sistemas simbólicos (SARMENTO, 2002). É necessário então que as professoras conheçam o que seus alunos estão assistindo, para que possam valorizar a 
cultura que os mesmos trazem para a sala de aula e mediar, inclusive os conteúdos televisivos que compõem o seu repertório lúdico, ensinando-os a brincar e a arte de aprender brincando.

Desta forma, a pesquisa buscou dialogar com as crianças e professores, a fim de encontrar respostas para entender a importância de se mediar as situações culturais que adentram o ambiente escolar, assim como refletir sobre a sua prática pedagógica. O contexto da Educação Infantil, na perspectiva apontada, pode se tornar um lugar de ricas aprendizagens, com experiências diversificadas e não apenas um espaço cuja meta é a alfabetização precoce.

\section{CONCLUSÕES}

Com os resultados alcançados pelos estudos, foi possível identificar que as mídias estão sim presentes no cotidiano das crianças, seja dentro do contexto familiar ou no contexto escolar. Essa relação é defendida pelos autores como um contato positivo, porém, pode ser compreendida de maneira negativa, quando a mediação que deve ser feita pelos pais/responsáveis, professores e demais adultos não ocorrem de forma a privilegiar a aprendizagem e valorizar os conhecimentos que os conteúdos midiáticos podem proporcionar para os interlocutores.

Foi possível através do levantamento bibliográfico sobre a temática, e as observações realizadas nas aulas junto às crianças, compreender que os elementos ludicidade e conteúdos televisivos estão muito presentes no contexto escolar, todavia, uma visão negativa demonstrada por parte dos professores dificulta uma interlocução entre essas temáticas e que podem ser enriquecedoras no processo de ensino-aprendizagem e na promoção do desenvolvimento da criança na Educação Infantil.

\section{REFERÊNCIAS BIBLIOGRÁFICAS}

BROUGÈRE, G. A criança e a cultura lúdica. Revista da Faculdade de Educação, São Paulo, vol.24, n.2., jul/dez, 1998.

BUCKINGHAM, D. Crescer na era das mídias eletrônicas. São Paulo: Loyola, 2007, 301p.

GIRARDELLO, G. Imaginação infantil e as histórias da TV. Disponível em: <www.aurora.ufsc. br/artigos/artigos_imaginacao.htm>. Acesso em: jun. 2008.

LUDKE, M.; ANDRÉ, M. E. D. A. Pesquisa em Educação: abordagens qualitativas. São Paulo: EPU, 1986.

REDIN, M. M. Crianças e suas culturas singulares. In: MÜLLER, F.; CARVALHO, A. M. A. (orgs.). Teoria e prática na pesquisa com crianças: Diálogos com William Corsaro. São Paulo: Cortez, 2009. 
RICHARDSON, R. J. Pesquisa Social: métodos e técnicas. São Paulo: Atlas, 1989.

SARMENTO, M. J. Infância, Exclusão Social e Educação como utopia realizável. In.: Educação e Sociedade, n.78, abril 2002.

SARMENTO, M. J.. As culturas da Infância nas encruzilhadas da 2o modernidade. 2003. Disponível em <http://cedic.iec.uminho.pt/cedic/Textos_de_Trabalho/textos/encruzilhadas.pdf>. Acesso em 05/05/2007.

VIÉGAS, L. S. Reflexões sobre a pesquisa etnográfica em Psicologia e Educação. Diálogos Possíveis, Bahia, n. 09, jan/jun, 2007. 